\title{
Investigating the forced convection of magnetic nanofluids
}

\author{
Dmitriy Guzei ${ }^{1,2, *}$, Andrey Minakov ${ }^{1,2}$, Maxim Pryazhnikov ${ }^{1,2}$, and Konstantin Meshkov ${ }^{1}$ \\ ${ }^{1}$ Siberian Federal University, 660041, Krasnoyarsk, Russia \\ ${ }^{2}$ Institute of Thermophysics SB RAS, 630090, Novosibirsk, Russia
}

\begin{abstract}
Experimental study of the magnetic nanofluids forced convection in a constant magnetic field was carried out. Dependence study of the magnetic nanofluid heat transfer coefficient on the effect of a constant magnetic field was made. The effect of a constant magnetic field on the pressure drop during the magnetic nanofluid flow was shown.
\end{abstract}

\section{Introduction}

One of the solutions to the problem of heat transfer performance enhancement could be the use of so called nanofluids, which are fluids containing nanoparticles of various composition. The use of electromagnetic fields is a promising way to control the properties of nanofluids. The magnetic field can be influenced by nanofluids prepared from ferromagnetic materials (ferromagnetic nanofluids), for example, from iron nanoparticles, its oxide $\left(\mathrm{Fe}_{3} \mathrm{O}_{4}\right)$, nickel etc. Such fluids can be extremely useful in many applications.

There are lots of works study of nanoparticles transport in the magnetic field in the channels [1-3]. Sundar et al. [1] studied turbulent forced convection heat transfer and friction factor of $\mathrm{Fe}_{3} \mathrm{O}_{4}$ magnetic nanofluid in a tube in the absence of magnetic field and developed correlations for the estimation of Nusselt number and friction factor. Their results show that the heat transfer coefficient is enhanced by $30.96 \%$ and friction factor by $10.01 \%$ at $0.6 \%$ volume fraction compared to the base fluid. Recently, Ghofrani et al. [2] investigated the effect of constant and alternating magnetic fields on the forced convection heat transfer in a short tube. They showed that increasing the alternating magnetic field frequency increases the heat transfer up to of $27.6 \%$ in low Reynolds numbers. Lajvardi, et al.[3] experimentally studied the convective heat transfer of water $-\mathrm{Fe}_{3} \mathrm{O}_{4}$ ferrofluid flowing through a tube in laminar regime in the presence of magnetic field perpendicular to the flow direction. They performed their experiments on different ferrofluids concentration and at different magnetic positions in magnetic fields. They concluded that by improving the thermo physical properties of the ferrofluids, heat transfer can be attributed in the presence of magnetic field.

\section{Description of the experimental setup}

Experimental study of the forced convection of magnetic nanofluids in a constant magnetic field was carried out. Experiments with nanofluid forced convection were performed at the

*Corresponding author: gudimas@yandex.ru 
experimental stand of the Department of Thermophysics of the Siberian Federal University. The experimental unit is a loop with a circulation coolant. The experimental unit diagram is shown in Fig 1a.

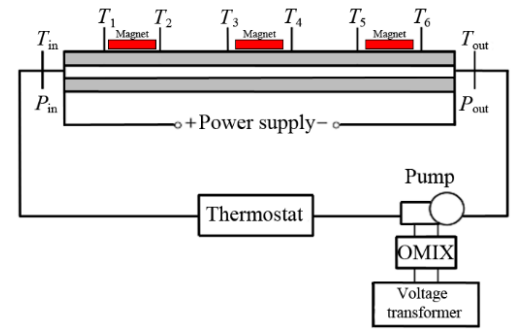

a)

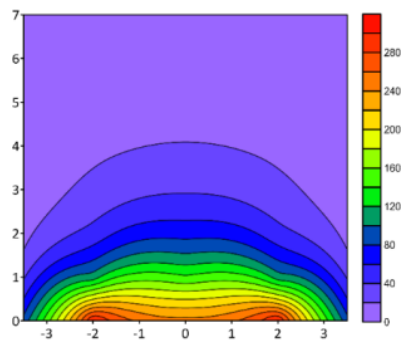

b)

Fig. 1. a) The experimental unit diagram; b) The magnetic field induction over the magnet (mT).

The working fluid is pumped to the heated test section from the accumulator tank. The gear pump WT30001 was used for pumping a nanofluid. Pump drives provide the ability to pump different fluids at a flow rate from 85.7 to $2571.4 \mathrm{ml} / \mathrm{min}$.

After passing the heated section, the liquid enters the heat exchanger and gives heat to the thermostat. The working fluid flow rate in the circuit is regulated by control valves. Monitoring of the flow rate in the circuit is carried out by flowmeter. The heated section is a stainless steel tube with a diameter $10 \mathrm{~mm}$ and a length of $1 \mathrm{~m}$. The wall thickness is $1 \mathrm{~mm}$. Electric current is supplied to the wall for heating. This ensures the conditions of constant heat flow on the wall. Heating power is regulated by LATR. 6 copper-constantan thermocouples are fixed on the wall at an equal distance from each other to measure the local temperature of the tube. The temperature is read by the TPM-200 meters. The temperature at the inlet and outlet of the heated section is measured by thermocouples. In this case, the thermocouple for measuring the ambient temperature at the circuit outlet is located at a considerable distance from the heated section end to ensure ambient temperature uniformity at the measurement site. The circuit section from the heater to the ambient temperature measurement site was heat insulated. The drop pressure study at the inlet and outlet of the heated section was also measured. The pressure drop over the length of the working section is measured by a differential pressure gauge OWEN PD200. The experimental unit for measuring heat transfer coefficient was tested using the known empirical data for the heat transfer of pure water.

Three permanent neodymium magnets with dimensions $50 \times 30 \times 10 \mathrm{~mm}$ were used to create a magnetic field. The magnetic field intensity around the magnet was measured with a milliteslameter TPU-02. The distribution of the magnetic field induction over the magnet is shown in Fig. 1b. The maximum value of the magnetic induction near the magnet is of the order of $0.3 \mathrm{~T}$. In experiments, the magnets were located in the immediate vicinity of the heated section at the same distance from each other.

Iron oxide nanoparticles $\mathrm{Fe}_{3} \mathrm{O}_{4}$ were used to prepare the nanofluid. The average particle size was $100 \mathrm{~nm}$. Distilled water was used as a base fluid. The volume density of nanoparticles was $0.25 \%$. A standard two-step method was used to prepare the nanofluid. Suspensions were processed in an ultrasonic bath "Sapphire TC-10338". The nanofluids were free of surfactants.

The nanofluid viscosity was measured at a Brookfield DV2T rotary viscometer with a low viscosity ULA adapter (0). The measurement accuracy for the viscosity coefficient was not less than $2 \%$. The viscometer was calibrated with distilled water and ethylene glycol before the measurements. The results were in good agreement with the reference data. The viscosity coefficients of water and nanofluid is shown in Table 1. 
Table 1. Viscosity of water and nanofluid.

\begin{tabular}{|c|c|c|}
\hline & Water & Nanofluids $\mathrm{Fe}_{3} \mathrm{O}_{4} 0.25 \%$ \\
\hline Viscosity, cP & 0.902 & 0.929 \\
\hline
\end{tabular}

The coefficient of thermal conductivity of nanofluids was measured using a nonstationary hot wire method. The detailed description of the installation and its testing is given in [4].

\section{Experimental results}

The average and local values of the heat transfer coefficient at the channel walls were measured as a result of experiments. The dependences of the heat transfer coefficient on the Reynolds number for a nanofluid with a volume density of $0.25 \%$ were obtained with and without the magnetic field action. A strong influence of a constant magnetic field on the forced convection of the magnetic nanofluid was shown during the experiments. The graph of the average heat-transfer coefficient versus time (Fig. 2) shows that the heat transfer coefficient increases with the constant magnetic field action. Measurements were made without the magnetic field action in the interval from 0 to $100 \mathrm{~s}$. After that, three permanent magnets were installed near the working section wall, and the recording of the measured parameters was not interrupted. The average heat transfer coefficient was shown to increase.

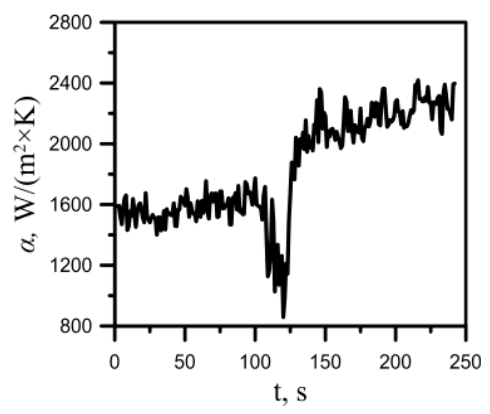

Fig. 2. Dependence of the average heat transfer coefficient on time.

The magnetic field action on the nanofluid heat transfer coefficient with a nanoparticle volume density of $0.25 \%$ was investigated. The influence of the magnetic field intensifies the average heat transfer coefficient by $13 \%$ relative to the base fluid at a fixed flow rate, while the nanofluid heat transfer coefficient without the magnetic field influence is $10 \%$ below pure water. The dependence of the heat transfer coefficient on the flow rate is shown in Fig. 3a. At a fixed Reynolds number the average heat transfer coefficient of a magnetic nanofluid with a particle concentration of $0.25 \%$ increases by $35 \%$ relative to the base fluid with the static magnetic field action produced by three magnets (Fig. 3b).

The increasing effect of the heat transfer coefficient takes place for a fixed value of the Reynolds number and the coolant flow. While the heat transfer coefficient with increasing particle concentration can decrease with a fixed value of the coolant flow rate in turbulent heat exchange of nonmagnetic nanofluids or nanofluids without the magnetic field influence, investigated earlier [5]. 


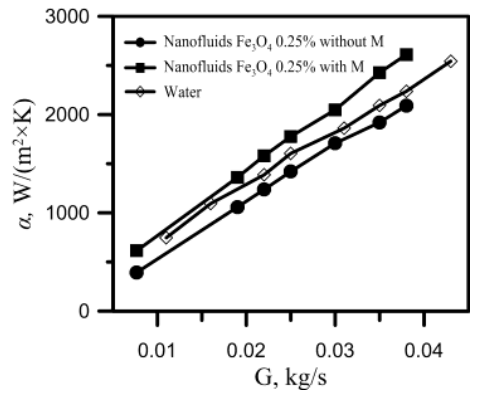

a)

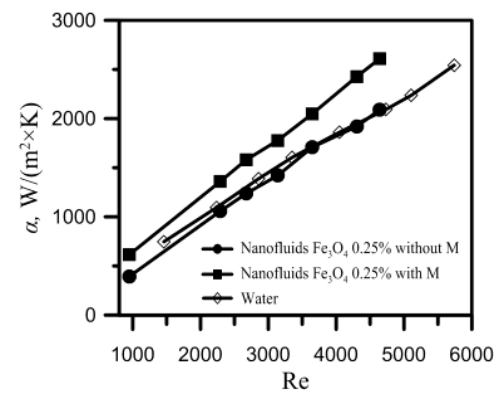

b)

Fig. 3. Dependence of the average heat transfer coefficient on flow rate a) and Reynolds number b) with and without the magnetic field action $\left(\mathrm{Fe}_{3} \mathrm{O}_{4} 100 \mathrm{~nm}, 0.25 \%\right)$.

Experiments have established that the magnetic field has a significant effect on the pressure drop in the working section. The graph of the pressure drop in the working section depending on the Reynolds number is shown in Fig. 4. In the experiments it was shown that three magnets located along the tube increase the pressure drop in the channel by $21 \%$ compared to the pressure drop without the field for a nanofluid with a volume density of $\mathrm{Fe}_{3} \mathrm{O}_{4}$ particles $0,25 \%$. The pressure drop magnitude for a nanofluid with a particle volume density of $0.25 \%$ without a magnetic field at a constant Reynolds number is $30 \%$ higher the pressure drop for the base fluid.

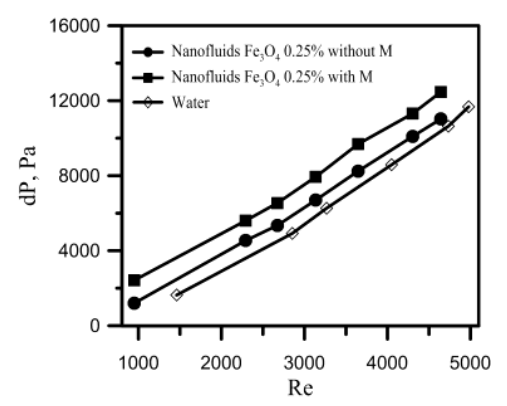

Fig. 4. Dependence of the pressure drop on Reynolds number with and without the magnetic field action.

The reported study was funded by Russian Foundation for Basic Research, Government of Krasnoyarsk Territory, Krasnoyarsk Region Science and Technology Support Fund, the research project №16-48-243061.

\section{References}

1. L.S. Sundar, M.T. Naik, K.V. Sharma, M.K. Singh, T.Ch. Reddy, Exp. Therm. Fluid Sci. 37, 65 (2012)

2. A. Ghofrani, M.H. Dibaei, A. Hakim Sima, M.B. Shafii, Exp. Therm. Fluid Sci. 49, 193 (2013)

3. M. Lajvardi, J. Moghimi-Rad, I. Hadi, A. Gavili, T.D. Isfahani, F. Zabihi, J. Sabbaghzadeh, J. Magn. Magn. Mat. 322, 35083 (2010)

4. A.V. Minakov, V.Ya. Rudyak, D.V. Guzei, M.I. Pryazhnikov, A.S. Lobasov, J. Eng. Phys. Thermophys 88, 149 (2015)

5. A.V. Minakov, D.V. Guzei, M.I. Pryazhnikov, V.A. Zhigarev, V.Ya. Rudyak, Int. J. Heat Mass Transfer 102, 745 (2016) 